\title{
Enhancement of Esterification of Propionic Acid with Isopropyl Alcohol by Pervaporation Reactor
}

\author{
Ajit P. Rathod, ${ }^{1}$ Kailas L. Wasewar, ${ }^{1,2}$ and Chang Kyoo Yoo ${ }^{2}$ \\ ${ }^{1}$ Advance Separation and Analytical Laboratory (ASAL), Department of Chemical Engineering, \\ Visvesvaraya National Institute of Technology (VNIT), Nagpur 440010, India \\ ${ }^{2}$ Environmental Management \& Systems Engineering Lab (EMSEL), Department of Environmental Science and Engineering, \\ College of Engineering, Kyung Hee University, Seocheon-dong 1, Giheung-gu, Yongin-si, Gyeonggi-do 446-701, Republic of Korea
}

Correspondence should be addressed to Kailas L. Wasewar; k_wasewar@rediffmail.com and Chang Kyoo Yoo; ckyoo@khu.ac.kr

Received 31 May 2013; Accepted 24 December 2013; Published 6 February 2014

Academic Editor: Saima Q. Memon

Copyright (C) 2014 Ajit P. Rathod et al. This is an open access article distributed under the Creative Commons Attribution License, which permits unrestricted use, distribution, and reproduction in any medium, provided the original work is properly cited.

With increasing cost of raw materials and energy, there is an increasing inclination of chemical process industries toward new processes that result in lesser waste generation, greater efficiency, and substantial yield of the desired products. Esterification is a chemical reaction in which two reactants carboxylic acid and alcohol react to form an ester and water. This reaction is a reversible reaction and the equilibrium conversion can be altered by varying the process parameters. Pervaporation reactor can enhance the conversion by shifting the equilibrium of reversible esterification reactions. Polyvinyl alcohol-polyether sulfone composite hydrophilic membrane was used for pervaporation-assisted esterification of propionic acid with isopropyl alcohol. The experiments were carried out in the presence of sulphuric acid as a catalyst at $50^{\circ} \mathrm{C}$ to $80^{\circ} \mathrm{C}$ with various reactants ratios. The esterification was carried out for catalyst loadings of $0.089 \mathrm{kmol} / \mathrm{m}^{3}$ to $0.447 \mathrm{kmol} / \mathrm{m}^{3}$. The molar ratios of isopropyl to propionic acid used for the experiment were 1 to 1.5. Maximum conversion was obtained for the ratio of 1.4. Also effect of other parameters such as process temperature and catalyst concentration was discussed. It was found that the use of pervaporation reactor increased the conversion of the propionic acid considerably.

\section{Introduction}

Esterification reaction is a classic example of an equilibriumlimited reaction. The conversion is generally low due to limits imposed by thermodynamic equilibrium. An ester and water as byproducts were obtained from this reaction. Esters are widely used in various process industries. It is necessary to shift the position of the equilibrium to the ester side by either using a large excess of one of the reactants (generally the alcohol). The use of a large excess of reactant increased the cost for separation [1]. Pervaporation reactor shows potential alternative due to rate-controlled separation process and low-energy utilization as compared to distillation. Further, pervaporation can be operated at a temperature that matches the optimal temperature for reaction with an appropriate membrane. The last characteristic is mainly important for esterifications due to temperature constraints [2].
Pervaporation membrane reactors have been studied for esterification of acetic acid and ethanol [1], acetic acid and isopropanol [3], oleic acid and ethanol [4,5], tartaric acid and ethanol [6], oleic acid and butanol [7], and valeric acid and ethanol [8] with various acids or lipases as catalysts. In some cases, the membrane itself is catalytically active [9].

There is increasing attention towards the use of membrane processes to increase the yield of equilibrium-limited reactions by selective elimination of a reaction product [10].The review on PV separation of water-acetic acid mixtures and its important results are detailed [11]. Novel poly(vinyl alcohol)-titanium dioxide $\left(\mathrm{PVA}-\mathrm{TiO}_{2}\right)$ mixed matrix membranes prepared by incorporating nano-sized titanium dioxide $(21 \mathrm{~nm})$ and titanium dioxide surface modified with polyaniline (PANI) into PVA and cross-linked with glutaraldehyde [12]. Poly(vinyl alcohol) (PVA)-based nanocomposite membranes were prepared by coprecipitation of 
different amounts of $\mathrm{Fe}(\mathrm{II})$ and $\mathrm{Fe}(\mathrm{III})$ taken in an alkaline medium and their pervaporation (PV) performances were investigated to dehydrate isopropanol, 1,4-dioxane and tetrahydrofuran (THF) from aqueous feeds containing 10-20 wt.\% of water in isopropanol and 1,4-dioxane, 5- $15 \mathrm{wt} . \%$ of water in THF [13]. Mixed matrix membranes of poly(vinyl alcohol) (PVA), loaded with phosphomolybdic heteropoly acid (HPA) and cross-linked with glutaraldehyde prepared by the solution casting technique. Pervaporation (PV) experiments were performed to separate water-isopropanol feed mixtures [14]. Mixed matrix membranes of sodium alginate $(\mathrm{NaAlg})$ and poly(vinyl alcohol) (PVA) containing 5 and $10 \mathrm{wt}$. $\%$ silicalite- 1 particles were fabricated by solution casting method and the cured membranes were cross-linked with glutaraldehyde. These membranes were used in pervaporation (PV) dehydration of isopropanol [15]. Mixed matrix membranes of sodium alginate $(\mathrm{NaAlg})$ were prepared by solution casting incorporating $2.5,5,7.5$, and $10 \mathrm{wt} . \%$ of zeolite beta particles. The membranes thus prepared were cross-linked with glutaraldehyde and tested for the pervaporation (PV) dehydration of ethanol and acetic acid [16]. Filled mixed matrix membranes (MMM) of sodium alginate (NaAlg) were prepared by solution casting method and were filled with $4 \mathrm{~A}$ zeolite particles in varying compositions from 0 to $10 \mathrm{wt} \%$ with respect to weight of NaAlg polymer. Membranes were crosslinked with glutaraldehyde and tested for pervaporation (PV) dehydration of acetic acid and ethanol [17]. A very few work has been available on pervaporation reactor for esterification reactions of propionic acid with isopropanol. The reaction studied for the application of pervaporation reactor is an esterification of propionic acid with isopropanol to give isopropyl propionate and water:

$$
\mathrm{C}_{3} \mathrm{H}_{6} \mathrm{O}_{2}+\mathrm{C}_{3} \mathrm{H}_{8} \mathrm{O} \longleftrightarrow \mathrm{C}_{6} \mathrm{H}_{12} \mathrm{O}_{2}+\mathrm{H}_{2} \mathrm{O} .
$$

In the present paper, experiments were conducted for esterification of propionic acid with isopropanol coupled with pervaporation and without pervaporation. Also effect of various parameters such as initial mole ratio of isopropyl alcohol over propionic acid, process temperature, and catalyst concentration on the performance of pervaporation reactor was discussed.

\section{Experiment}

2.1. Membrane. Polyvinyl alcohol-polyether sulfone (PVAPES) composite kind of hydrophilic membrane was used in flat sheet module of pervaporation reactor (supplied by Permionics Membranes Pvt. Ltd., India, size of test cell: $240 \mathrm{~mm} \times 180 \mathrm{~mm} \times 25 \mathrm{~mm}$, and MOC of test cell SS-316) with active membrane area $0.0155 \mathrm{~m}^{2}$.

2.2. Thermogravimetric Analysis (TGA). Thermal stability of PVA-PES membrane was determined with SII Co. Exstar TG/DTA (Japan). Thermogravimetric analyzer was used in order to know their upper temperature limit. The sample $(6 \mathrm{mg})$ was placed in an aluminum pan and heated over a temperature range of 30 to $400^{\circ} \mathrm{C}$ at a heating rate of $10^{\circ} \mathrm{C} \mathrm{min}^{-1}$.

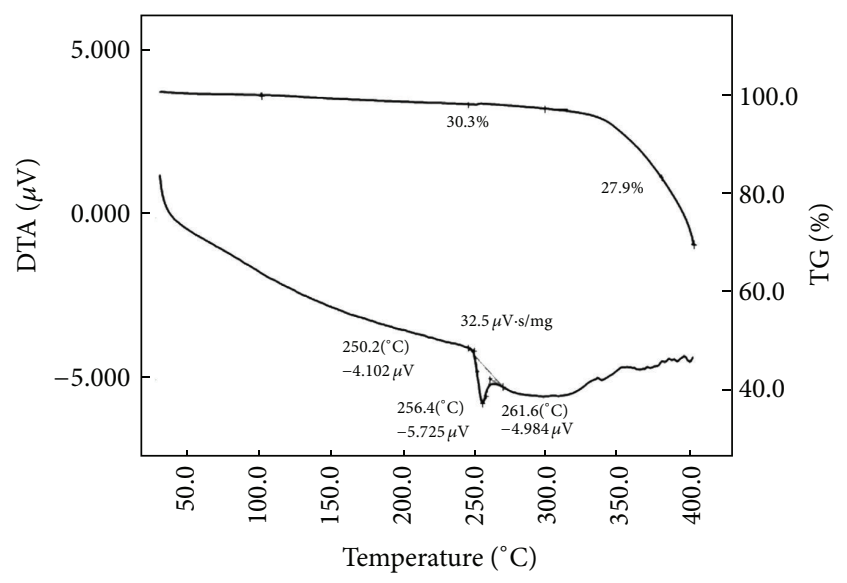

FIGURE 1: Thermogravimetric analyzer (TGA) analysis of membrane of PVA-PES.

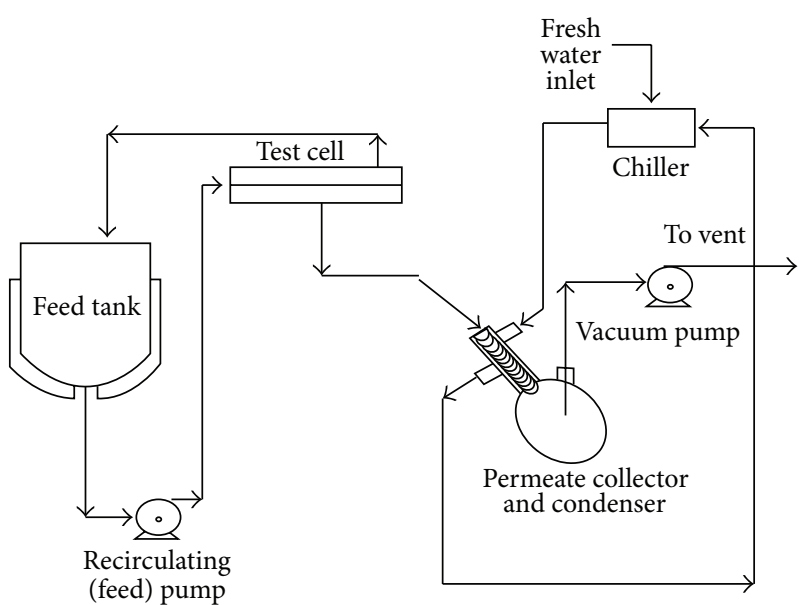

FIgURE 2: Typical diagram of pervaporation reactor (PVR).

The thermal stability was determined over temperature range from $30-400^{\circ} \mathrm{C}$. In PVA-PES membrane, the onset of thermal decomposition started at $250.2^{\circ} \mathrm{C}$ and decomposition ends around $261.6^{\circ} \mathrm{C}$ with melting point $256.4^{\circ} \mathrm{C}$ as shown in Figure 1 observed total weight loss was $30.3 \%$. This shows a high thermal stability of the PVA-PES membrane.

2.3. Apparatus. Esterification reaction and separation were carried out in a laboratory-scale semibatch pervaporation reactor supplied by Permionics Membranes Pvt. Ltd., India (Figure 2). A vacuum of less than 8 mbar was generated with a vacuum pump (Make: ILMVAC GmbH; Model: Diaphragm pump chem. Resistant, MPC 301Z). Cold water was supplied from a chiller to condense the permeate water vapor. For pervaporation experiments, the flat sheet membrane test cell was used. Recirculation pump was used (Make: Ravel Hiteks pvt Ltd; Model: RH-P-120L) to circulate the retentate solution.

2.4. Esterification. Analytical grade chemicals were used in the esterification reaction. The CAS number, source, and 


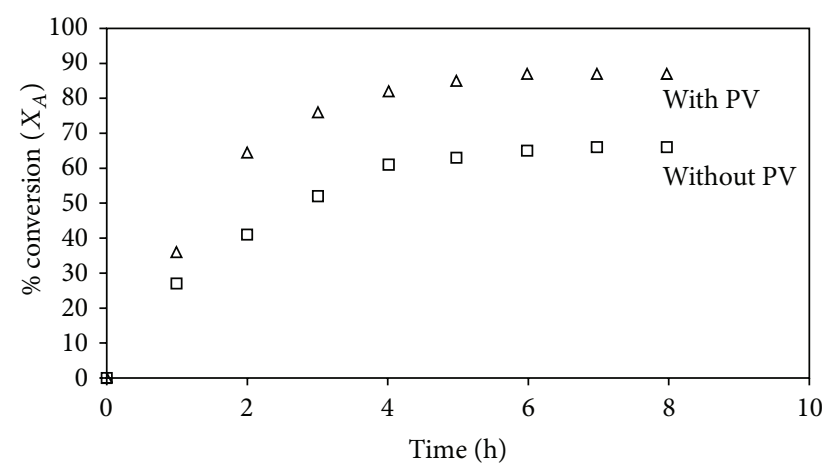

Figure 3: Comparison of experimental results for propionic acid conversion $\left(T=80^{\circ} \mathrm{C} ; C_{C}=0.358 \mathrm{kmol} / \mathrm{m}^{3} ; R=1.4 ; S / V=\right.$ $\left.15.19 \mathrm{~m}^{2} / \mathrm{m}^{3}\right)$ : with PV $(\triangle)$ and without PV $(\square)$.

grades of the chemicals used are as follows: propionic acid (CAS 79-09-4, Qualigens 99\%), isopropyl alcohol (CAS 6763-0, Qualigens 99\%), and Sulphuric acid (CAS 7664-93-9, Qualigens 99.9\%). All the chemicals were used without any further treatment. Esterification experiments utilized the equivalent mole of propionic acid $(500 \mathrm{~mL})$ and isopropyl alcohol $(510 \mathrm{~mL})$, giving a mole ratio of isopropyl alcohol to propionic acid as $1: 1$. Experiments were carried out with sulphuric acid as a catalyst. The water was removed by applying vacuum on the permeate side. Permeate was condensed and collected in round bottom flask.

2.5. Analysis. The permeate composition and the amount of product (isopropyl propionate) in reaction mixtures were obtained by titration with $0.125 \mathrm{~N} \mathrm{NaOH}$. Few titration was performed in triplicate and results were obtained in the range of $\pm 3 \%$, which is acceptable.

\section{Results and Discussion}

Esterification with and without pervaporation was carried out in a laboratory-scale pervaporation reactor. Effect of various parameters such as process temperature $\left(50-80^{\circ} \mathrm{C}\right)$, initial mole ratio of isopropyl alcohol over propionic acid (1-1.5), and catalyst concentrations that were varied from 0.089 to $0.447 \mathrm{kmol} / \mathrm{m}^{3}$ on the performance of pervaporation reactor was carried out. The results are discussed in further section.

From Figure 3, it was found that pervaporation enhanced the conversion more than without pervaporation. In case of pervaporation, considerable enhancement was observed and the conversion was increased from its equilibrium value of $66 \%$ to $87 \%$ using a PVA-PES membrane. This membrane was the most selective one for water transport of membranes used in this work [18], if the removal of water is indeed the major mechanism for the enhancement of yield.

Catalyst concentration may be an alternative way to accelerate ester production [19]. In view of this, the catalyst concentration was varied from $0.089 \mathrm{kmol} / \mathrm{m}^{3}$ to $0.447 \mathrm{kmol} / \mathrm{m}^{3}$.The experimental results for conversion of propionic acid during pervaporation process over various catalyst concentrations were presented in Figure 4. It can be

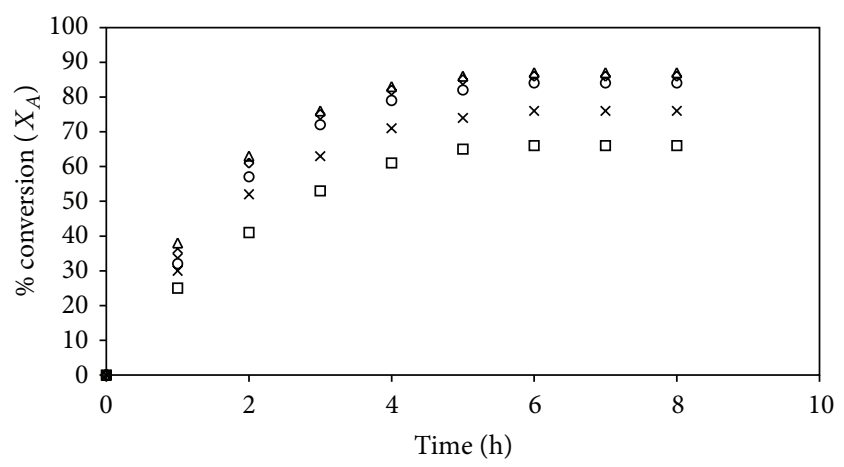

FIGURE 4: Effect of change in catalyst concentration on conversion of propionic acid $\left(T=80^{\circ} \mathrm{C} ; R=1.4 ; S / V=15.19 \mathrm{~m}^{2} / \mathrm{m}^{3}\right): C_{C}=$ $0.089 \mathrm{kmol} / \mathrm{m}^{3}(\square), C_{C}=0.179 \mathrm{kmol} / \mathrm{m}^{3}(\times), C_{C}=0.268 \mathrm{kmol} / \mathrm{m}^{3}$ (○), $C_{C}=0.358 \mathrm{kmol} / \mathrm{m}^{3}(\diamond), C_{C}=0.447 \mathrm{kmol} / \mathrm{m}^{3}(\triangle)$.

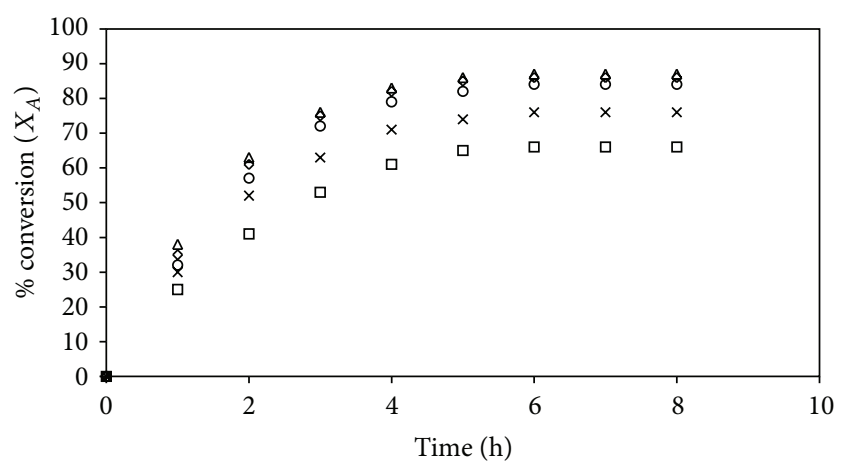

FIGURE 5: Effect of change in ratio of initial reactants on conversion of propionic acid $\left(T=80^{\circ} \mathrm{C} ; C_{C}=0.358 \mathrm{kmol} / \mathrm{m}^{3} ; \mathrm{S} / \mathrm{V}=\right.$ $\left.15.19 \mathrm{~m}^{2} / \mathrm{m}^{3}\right): R=1(\square), R=1.2(\times), R=1.3(0), R=1.4(\diamond), R=$ $1.5(\triangle)$.

seen that the conversion is increasing with catalyst concentration. At higher concentration of catalyst, the percentage in conversion is also increasing but not with much significance $(<5 \%)$. Hence, catalyst concentration of $C_{C}=0.358 \mathrm{kmol} / \mathrm{m}^{3}$ is optimal.

Figure 5 depicts the effect of initial molar reactant ratio on the propionic acid conversion. The reactant ratio was varied from 1 to 1.5 for fixed values of the other parameters. The higher conversion was observed for higher ratios. It can be found that $R$ played a part in reaction rate but exerted no effect on kinetics of PV [20].

\section{Conclusion}

Experiments for esterification of propionic acid with isopropyl alcohol coupled with and without pervaporation were carried out. The performance of pervaporation reactor was analyzed by studying effect of various parameters such as temperature, catalyst concentration, and reactant ratio. Using pervaporation reactor considerable enhancement was observed and the conversion of propionic acid was increased from its equilibrium value of $66 \%$ to $87 \%$ using a PVA-PES 
membrane. The presented data can be extended for study and design of pervaporation reactor for similar kind of reactions.

\section{Conflict of Interests}

The authors declare that there is no conflict of interests regarding the publication of this paper.

\section{References}

[1] Ó. de la Iglesia, R. Mallada, M. Menéndez, and J. Coronas, "Continuous zeolite membrane reactor for esterification of ethanol and acetic acid," Chemical Engineering Journal, vol. 131, no. 1-3, pp. 35-39, 2007.

[2] X. Feng and R. Y. M. Huang, "Studies of a membrane reactor: esterification facilitated by pervaporation," Chemical Engineering Science, vol. 51, no. 20, pp. 4673-4679, 1996.

[3] M. T. Sanz and J. Gmehling, "Esterification of acetic acid with isopropanol coupled with pervaporation. Part II. Study of a pervaporation reactor," Chemical Engineering Journal, vol. 123, no. 1-2, pp. 9-14, 2006.

[4] H. Kita, S. Sasaki, K. Tanaka, K. Okamoto, and M. Yamamoto, "Esterification of carboxylic acid with ethanol accompanied by pervaporation," Chemistry Letters, vol. 17, no. 12, pp. 2025-2028, 1988.

[5] K. Okamoto, M. Yamamoto, Y. Otoshi et al., "Pervaporationaided esterification of oleic acid," Journal of Chemical Engineering of Japan, vol. 26, no. 5, pp. 475-481, 1993.

[6] J. T. F. Keurentjes, G. H. R. Janssen, and J. J. Gorissen, "The esterification of tartaric acid with ethanol: kinetics and shifting the equilibrium by means of pervaporation," Chemical Engineering Science, vol. 49, no. 24, pp. 4681-4689, 1994.

[7] S. J. Kwon, K. M. Song, W. H. Hong, and J. S. Rhee, "Removal of water produced from lipase-catalyzed esterification in organic solvent by pervaporation," Biotechnology and Bioengineering, vol. 46, no. 4, pp. 393-395, 1995.

[8] X. Ni, Z. Xu, Y. Shi, and Y. Hu, "Modified aromatic polyimide membrane preparation and pervaporation results for esterification system," Water Treatment, vol. 10, no. 2, pp. 115-120, 1995.

[9] L. Bagnell, K. Cavell, A. M. Hodges, A. W.-H. Mau, and A. J. Seen, "The use of catalytically active pervaporation membranes in esterification reactions to simultaneously increase product yield, membrane permselectivity and flux," Journal of Membrane Science, vol. 85, no. 3, pp. 291-299, 1993.

[10] J. J. Jafar, P. M. Budd, and R. Hughes, "Enhancement of esterification reaction yield using zeolite A vapour permeation membrane," Journal of Membrane Science, vol. 199, no. 1, pp. 117-123, 2002.

[11] T. M. Aminabhavi and U. S. Toti, "Pervaporation separation of water-acetic acid mixtures using polymeric membranes," Designed Monomers and Polymers, vol. 6, no. 3, pp. 211-236, 2003.

[12] M. Sairam, M. B. Patil, R. S. Veerapur, S. A. Patil, and T. M. Aminabhavi, "Novel dense poly(vinyl alcohol)- $\mathrm{TiO}_{2}$ mixed matrix membranes for pervaporation separation of water-isopropanol mixtures at $30^{\circ} \mathrm{C}$," Journal of Membrane Science, vol. 281, no. 1-2, pp. 95-102, 2006.

[13] M. Sairam, B. V. K. Naidu, S. K. Nataraj, B. Sreedhar, and T. M. Aminabhavi, "Poly(vinyl alcohol)-iron oxide nanocomposite membranes for pervaporation dehydration of isopropanol, 1,4dioxane and tetrahydrofuran," Journal of Membrane Science, vol. 283, no. 1-2, pp. 65-73, 2006.

[14] S. B. Teli, G. S. Gokavi, M. Sairam, and T. M. Aminabhavi, "Mixed matrix membranes of poly(vinyl alcohol) loaded with phosphomolybdic heteropolyacid for the pervaporation separation of water-isopropanol mixtures," Colloids and Surfaces A, vol. 301, no. 1-3, pp. 55-62, 2007.

[15] S. G. Adoor, B. Prathab, L. S. Manjeshwar, and T. M. Aminabhavi, "Mixed matrix membranes of sodium alginate and poly(vinyl alcohol) for pervaporation dehydration of isopropanol at different temperatures," Polymer, vol. 48, no. 18, pp. 5417-5430, 2007.

[16] S. G. Adoor, L. S. Manjeshwar, S. D. Bhat, and T. M. Aminabhavi, "Aluminum-rich zeolite beta incorporated sodium alginate mixed matrix membranes for pervaporation dehydration and esterification of ethanol and acetic acid," Journal of Membrane Science, vol. 318, no. 1-2, pp. 233-246, 2008.

[17] S. D. Bhat and T. M. Aminabhavi, "Pervaporation-aided dehydration and esterification of acetic acid with ethanol using $4 \mathrm{~A}$ zeolite-filled cross-linked sodium alginate-mixed matrix membranes," Journal of Applied Polymer Science, vol. 113, no. 1, pp. 157-168, 2009.

[18] F. R. Chen and H. F. Chen, "Pervaporation separation of ethylene glycol-water mixtures using crosslinked PVA-PES composite membranes. Part I. Effects of membrane preparation conditions on pervaporation performances," Journal of Membrane Science, vol. 109, no. 2, pp. 247-256, 1996.

[19] Y. Zhu and H. Chen, "Pervaporation separation and pervaporation-esterification coupling using crosslinked PVA composite catalytic membranes on porous ceramic plate," Journal of Membrane Science, vol. 138, no. 1, pp. 123-134, 1998.

[20] Q. L. Liu and H. F. Chen, "Modeling of esterification of acetic acid with n-butanol in the presence of $\mathrm{Zr}\left(\mathrm{SO}_{4}\right)_{2} \cdot 4 \mathrm{H}_{2} \mathrm{O}$ coupled pervaporation," Journal of Membrane Science, vol. 196, no. 2, pp. 171-178, 2002. 

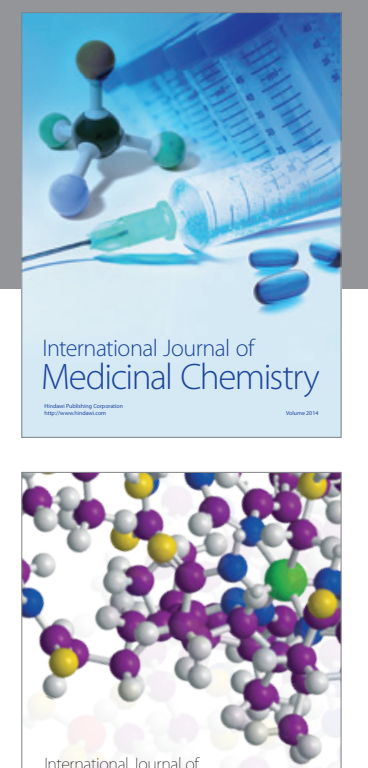

\section{Carbohydrate} Chemistry

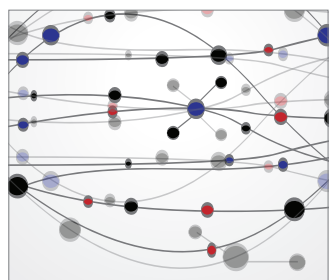

The Scientific World Journal
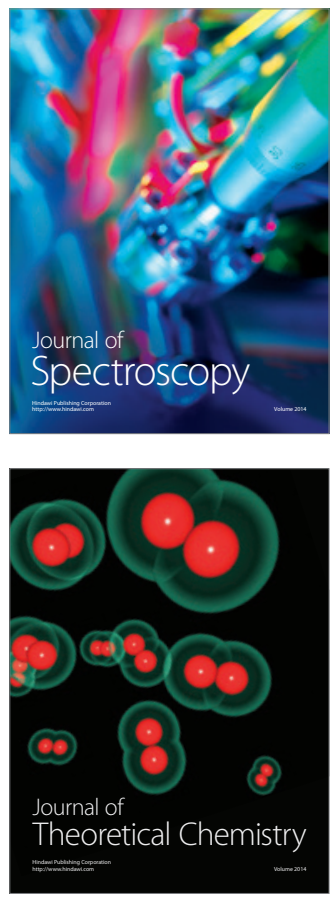
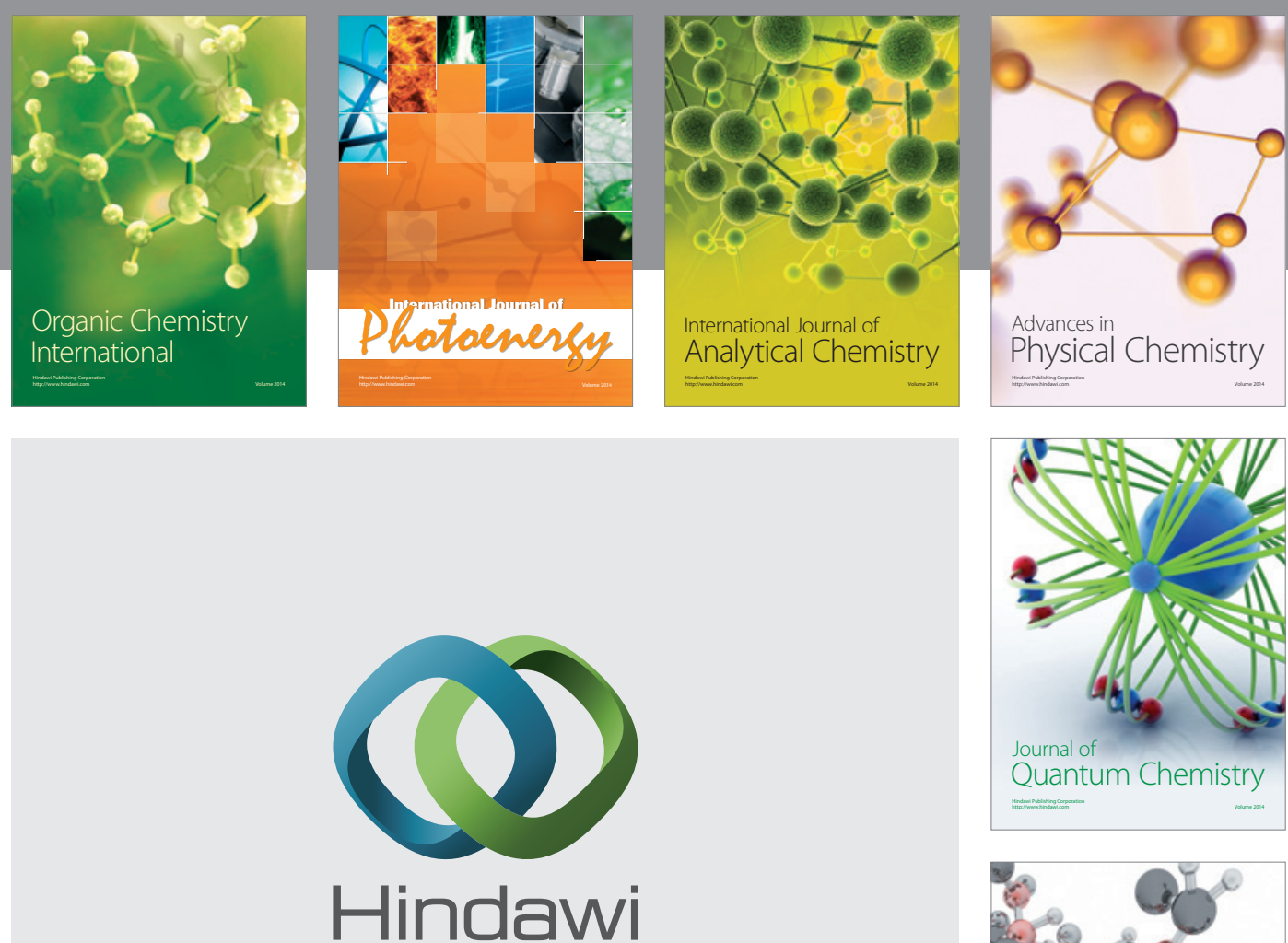

Submit your manuscripts at

http://www.hindawi.com

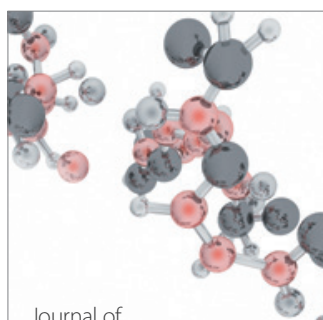

Analytical Methods

in Chemistry

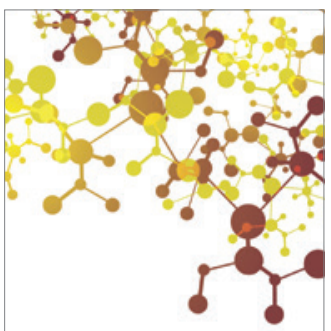

Journal of

Applied Chemistry

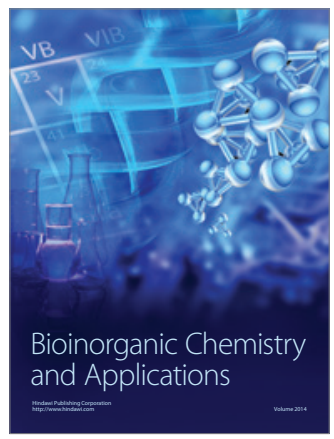

Inorganic Chemistry
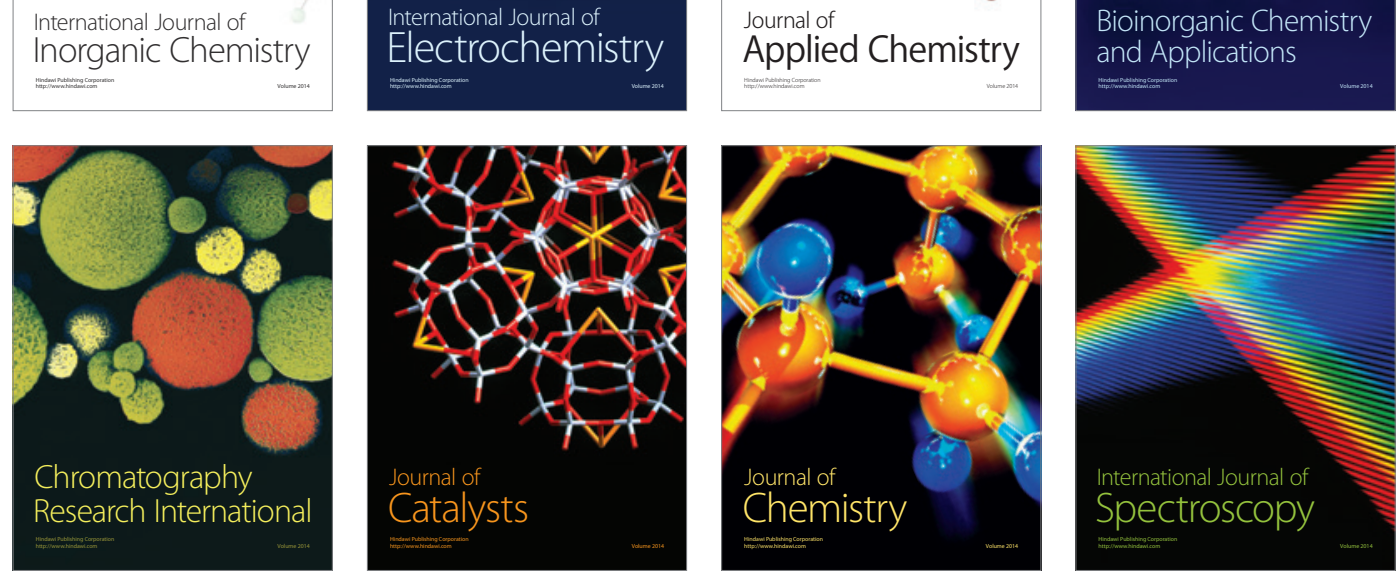